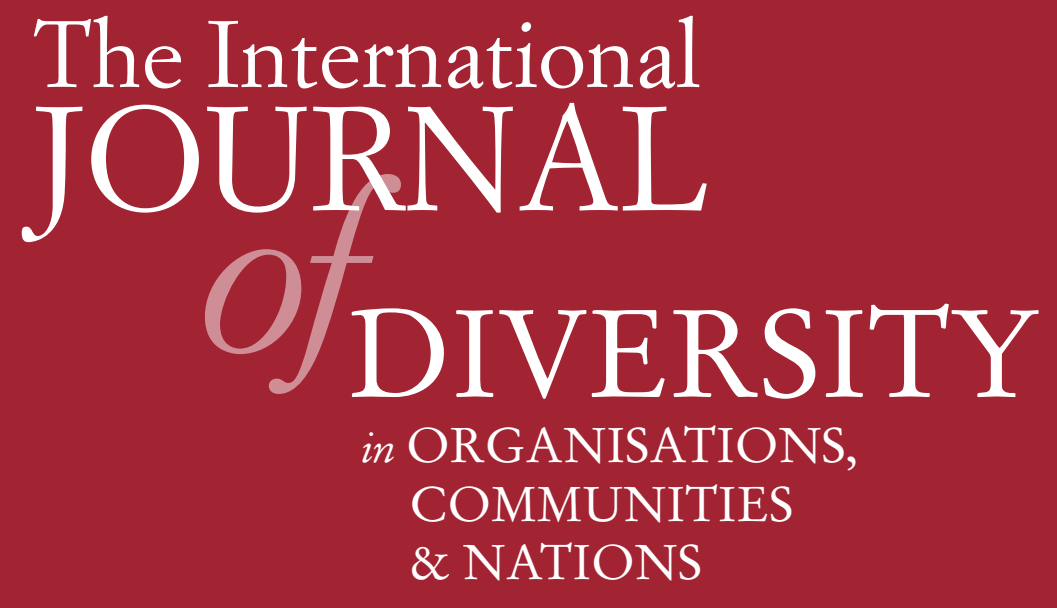

Volume 7, Number 5

Pan-Asian Identity in a Globalizing World

S. Jeanie Benson and Khairiah A Rahman 
THE INTERNATIONAL JOURNAL OF DIVERSITY IN ORGANISATIONS, COMMUNITIES AND NATIONS

http://www.Diversity-Journal.com

First published in 2007 in Melbourne, Australia by Common Ground Publishing Pty Ltd www.CommonGroundPublishing.com.

(C) 2007 (individual papers), the author(s)

(c) 2007 (selection and editorial matter) Common Ground

Authors are responsible for the accuracy of citations, quotations, diagrams, tables and maps.

All rights reserved. Apart from fair use for the purposes of study, research, criticism or review as permitted under the Copyright Act (Australia), no part of this work may be reproduced without written permission from the publisher. For permissions and other inquiries, please contact <cg-support@commongroundpublishing.com>.

ISSN: $1447-9532$

Publisher Site: http://www.Diversity-Journal.com

THE INTERNATIONAL JOURNAL OF DIVERSITY IN ORGANISATIONS, COMMUNITIES AND

NATIONS is a peer refereed journal. Full papers submitted for publication are refereed by Associate Editors through anonymous referee processes.

Typeset in Common Ground Markup Language using CGCreator multichannel typesetting system http://www.CommonGroundSoftware.com. 


\title{
Pan-Asian Identity in a Globalizing World
}

\author{
S. Jeanie Benson, Auckland University of Technology, New Zealand \\ Khairiah A Rahman, Auckland University of Technology, New Zealand
}

\begin{abstract}
For many East and South East Asian youth, global citizenship is an increasing reality. This raises new research questions of the process of acculturation and ethnic identity. East and South East Asian immigrants and student sojourners in Australia and New Zealand may embody multiple ethnic backgrounds, speak several regional languages and sometimes live for extended periods of time in two or more Asian states or country. This paper challenges the concept of ethnic essentialism or a single cultural adaptation and explores the notion of a regional Pan-Asian identity that extends beyond the barriers of the Asian continent to a globalizing world.
\end{abstract}

Keywords: Globalization, East and South East Asian, Australasia, Hybrid Cultural Identity, Cultural Identity

\section{Introduction}

$\mathrm{M}$

OVING BEYOND THEIR families and countries of origin, East and South East Asian international students must face new challenges of acculturation and develop a new sense of ethnic identity in a larger world context during their study-cycle. Nationality may indicate the home-country or state of the students, but it is an essentialist or static representation of the students' background and does not take into account the changing nature of identity shaped by the experiences and world-views of the students as they sojourn in New Zealand. The primary focus of this paper is to explore a case for a Pan-Asian ethnic identity for the respondents and to consider the likelihood of generalising this to other East and South East Asian international students.

The concept of Pan-Asian identity is offered on the premise of increasing global relationships on a variety of interconnecting spheres or scapes. East and South East Asian nationals are bound by proximity and by shared relationships on the four interconnected spheres or scapes suggested by Appadurai (2003). Technology, economic relationships, media ${ }^{1}$ and ideological networks are even more closely interlinked with stretched global relations which are inherent in globalization (Cochrane \& Pain, 2004). In the context of New Zealand based research, it is important to discard the notion that globalization is a Western phenomenon (McKay, 2004). It is in fact a vibrant force in operation throughout the entire Asian region, leading to complex interconnections based on shared regional association which is appar- ent in the East and South East Asian international students in this study. Importantly, , the formation of ASEAN (Association of the South east Asian Nations) in 1967 was founded on the need to maximise economic growth and maintain social security in the region. Membership grew from its original 5 member countries to 10 in 1997 and 13 in 1999. Some of the principles adopted by ASEAN include mutual respect for national identity, sovereignty and territorial integrity of member states with a view to establishing regional cooperation and safeguard collective interests(ASEAN website, 2007).

Four decades of political cooperation among such extensive network of nations have effected mutual confidence and affiliation of member countries. In examining the acculturation of the East and East Asian students in New Zealand, there is a unanimous sense of belonging to an existing and encompassing Asian community rather than national identity among the students, which suggests a strong case for the Pan-Asian identity.

The idea of a Pan-Asian identity is a logical development considering that behaviours, cultural practices and relationships are developed from shared mutual goals, languages, belief systems, history and geographical boundaries (Henders, 2004). This identity can seem narrow as most ethnicists would argue that ethnic specificity, based on racial elements, and can be essentialising and limiting. This is because it does not satisfactorily take into account the natural ebbs and flows of individual or group experiences as they sojourn or emigrate from their home-countries or states. In the case of a Pan-Asian identity though, the contested concept of ethnicity

\footnotetext{
${ }^{1}$ This is not to suggest that the mass media necessarily overlap or that these diverse states share the same history books or newspapers, but rather that the media scapes have a traditional awareness of the events and impacts of the nearby states due to cultural and family connections and historical events such as wars, invasion and trade.
}

THE INTERNATIONAL JOURNAL OF DIVERSITY IN ORGANISATIONS, COMMUNITIES AND NATIONS, VOLUME 7, NUMBER 5, 2007

http://www.Diversity-Journal.com, ISSN 1447-9532

(C) Common Ground, S. Jeanie Benson, Khairiah A Rahman, All Rights Reserved, Permissions: cg-support@commongroundpublishing.com 
as groups purely sharing racial or biological elements does not apply. In fact, in this age of increased globalization, ethnic specificity cannot encapsulate the shared experiences that multi-ethnic students undergo as sojourners away from their own families, countries or states. Critically, ethnic specificity also does not easily take into account the development of identity in cases where the parents are from different home-countries or states, or have different ethnic backgrounds based on other criteria such as religion.

East and South East Asian international students in New Zealand are already beyond their own national borders, and are exposed to new cultural ideas and this is doubly reinforced by their position as foreign students within the domestic tertiary education system. Tertiary education systems impart skills, but are also focused on introducing new ways of thinking, reasoning and problem-solving. In this specific instance, ethnic identity cannot be a static or unfolding historical process, because the [foreign] New Zealand environment offers opportunities and pressures for changing beliefs, values and the so called 'realities' of daily life in a foreign host country. Therefore for this analysis, a constructionist viewpoint offered by Nagel (1994) is used, which emphasises this personal selection in the process of identity boundary formation.

We can think of ethnic boundary construction as the shape of the shopping cart (size, number of wheels, composition etc.); ethnic culture then is composed of the things we put into the cart - art, music, dress, religion, norms, beliefs, symbols, customs. It is important that we discard the notion that culture is simply an historical legacy; culture is not a shopping cart that comes to us already loaded with a set of historical goods. Rather we construct culture by picking and choosing items from the shelves of the past and present. (p. 162).

Alongside this, is the critical notion that ethnic identity is also continually negotiated in conjunction with the perspectives of others (Barth, 1969 as cited in Nagel, 1994).

It is also critical for this study to offer a definition of ethnic groups as it is a contested concept that can be difficult to locate with precision. While the notion of ethnic construction can be fluid, the ethnic group itself can be described as,

ethnic groups can be understood as collectivities centred on contested, shifting claims to a shared and cultural identity, broadly defined, whether based on language, religion or other beliefs and customs, lineage, history, territory or way of life. (Henders, 2004, p.5)

\section{Methodology}

This analysis is based on an exploratory cross-section of East and South East Asian international students that were interviewed for a project primarily aimed at gaining their perceptions of New Zealanders and their life in New Zealand. The students were from two universities situated in Auckland, New Zealand where the $45 \%$ of the East and South East Asian international students across New Zealand are situated. (Ward, 2005). From a larger sample of 50 students from various East and South East Asian nations, a smaller sample of the first 15 students was extrapolated to form the basis of this analysis. ${ }^{2}$. The sample breaks down into ethnic sub groups of seven Malaysian students, three Chinese students, two Thai students and one student each from South Korea and Taiwan. The students were recruited through snowball sampling; therefore the uneven representation at this stage of the project is characteristic. Gender groups were also distributed unevenly with 12 females and just 3 males. Analyses have been performed at two levels. The first involves the differences within particular East and South East Asian groups and between East and South East Asian communities. These differences challenge any notion that suggests East and South East Asians share a single cultural identity. The second analysis looks at the features that unify them. This category highlights the students' awareness of shared commonalities and suggests the emergence of a Pan-Asian identity. Within each category, students' feedback and supporting literature are discussed to analyse and explain the cultural adaptation process and the formation of an emerging identity.

\section{Differences in the East and South East Asian Communities}

Although nationality was the primary descriptor, 11 of the 15 students interviewed, upon further discussion revealed that they had more than one ethnic identity. This is common for East and East and South East Asians who come from families with intermarriage unions. These students had one or more Chinese parents, but also had Malaysian or Thai nationalities. Also, some East and South East Asians originate from a multi-ethnic or multi-racial environ-

\footnotetext{
${ }^{2}$ While the geographies of East Asia are commonly associated with China, South Korea and Japan, the boundaries of this study were expanded to include students from East and South East Asian nations. This is particularly important in the social climate of New Zealand, where the term 'Asian' is commonly ascribed to East and East and South East Asian nations. This study excludes students from Central Asian nations such as India or Pakistan. In the New Zealand social climate, the term 'Indian' is usually applied by members of the public who perceive them to be 'different' in their origins and history.
} 
ment and develop ethnic affiliations to another group of people. In contrast, the Mainland Chinese ${ }^{3}$ groups did not share this multi-racial environment. When questioned more closely, one male respondent said "I am Chinese", which due to tone and emphasis was not interpreted as a misunderstanding but a restating of ethnic boundaries.

A substantially differing feature in this research, was the lack of willingness to mix socially between the other East and South East Asian ethnic groups. Specifically, the Chinese student interview data suggested they do not tend to mix easily on a social level with ethnic Chinese from Malaysia, Singapore or Taiwan. Although echoed by the Malaysian nationals as well, the Chinese students placed particular emphasis on this separation. One student claiming "my best friends are all from China like me" and another said "I will marry only a Chinese girl - it is not good to be with people you are not serious with". This separation is reflective of "Chinese proper" which is centred about the Yellow River area or Beijing, and is a theme which continues strongly through analyses of Chinese ethnic identity (Tu, 1994). China itself in contrast, is an extremely ethnically diverse region with 56 separate regional identities including Taiwan, Tibet and Mongolia (Weiwen \& Qingnan, 1993). Whether through language difficulties or national pride however, the Chinese students were unwilling to discuss ethnic diversity in China ${ }^{4}$.

At first glance then, it would seem that a PanAsian identity does not fit with perceptions of the Chinese of this particular sample. But with further analysis, it became clear that what differed for the Chinese students was the placement of China itself as the cultural centre, rather than the states of the west, and in this case - New Zealand. When pressed for more explanation however, one Chinese respondent asserted that [the Malaysian students] need to know that "China is the Mother Country; you should know your own family first". This was further supported by "the people from other Asian countries cannot be real Chinese if they do not know China". For this respondent then, China was not only central, but so too was the implicit belief that other people from the Chinese Diaspora would (or indeed should), feel similarly. This respondent clearly rated his relationship with China as primary, and felt that all people of Chinese descent should consider it a duty to do the same.

In contrast, the other East and South East Asian international students felt that the position of China should be less central. For the students from the mini dragons or East and South East Asian states such as Malaysia, Macau, or Singapore, there is a strong theme that this duty is already discharged through their fluency in Mandarin. The East and South East Asian students from Malaysia in that specific focus group all nodded assent at the sentiments of the Chinese respondent. Their actions however, suggest that their aims are to penetrate the western job market either by working in New Zealand or similar country, or by gaining skills that will keep them competitive in a changing job market in their home-states. Many of the students from the East and South East Asian countries or mini dragons, as they are sometimes known, they are already fluent in Mandarin and feel that this is sufficient acknowledgement of the centrality of China in their cultural heritage. This is congruent with the findings of Tu (1994), who believes that Chinese people (even after generations) in the diaspora see no need to yearn for a homeland as China is strong and continues to thrive and support them in their journeys throughout the world.

While sojourning in New Zealand, the East and South East Asian international students from Taiwan, Singapore or Malaysia (Mini Dragons), are also guided by recent political and social movements toward multicultural societies that incorporate all of the skills, languages and input from their members (Association of South East Asian Nations, n.d.). These states work toward a sense of "community" based on regional identity and this has been prioritised since its beginning on November 27, 1971 and has been developed and strengthened so that the entire region continues to reap the economic and ideological rewards of economic and social regionalism (Ibid). In search of the Chinese identity, the rise of countries such as Taiwan and Singapore has had a problematic effect on the Chinese identity, displacing the ideological notion of the Chinese centre and introducing a new ideology of regional identity $(\mathrm{Tu}$, 1994).

Ethnicity is to some extent bounded by a shared language as well as a sense of collective identity. This study itself is proof that a shared language does not necessarily point to a shared sense of ethnic identity. Speaking English does not guarantee a collective bond, but it can in some circumstances increase inter-ethnic communications and friendships. The Chinese Malaysian and the Thai respondents all reported difficulty in understanding the Mandarin spoken by other nationalities. This difficulty did not inhibit being understood while ordering food from New Zealand "Asian” restaurants, it was however, generally agreed, that this inhibited lengthy dialogue

\footnotetext{
${ }^{3}$ As China itself is such a vast state, and some definitions of its actual borders may be in political or social dispute, it is important to make this definition for the purpose of this study.

${ }^{4}$ Taking into account Confucian values, the silence on criticism may be due to the respect that the individual is expected to show for the state itself (De Bary, 2000).
} 
about "feelings inside" as one Thai respondent described it. The Malaysian students especially, preferred "to talk Mandarin to our Malaysian and Singapore friends" rather than to Chinese or other nationalities. This again, points to the centrality of Chinese value placed on high culture in which the subtleties of Beijing based language and accent takes priority over the regional variations (Tu, 1994).

For the East and South East Asian international students however, there was a distinct prevalence of multi-lingualism, 7 of them spoke at least three languages. English, Mandarin and Malay were the most common choices, but there were two notable exceptions of French and Arabic. This is a common feature for students who come from East and South East Asian nations and among families who travel and have to acquire new languages for social survival. In their work on Vietnamese migrants in Australia, Nguyen \& King (2004), used the term Viet kieu to refer to their model of adapted culture and travel behaviour. In Australia, the Viet kieu is described as having "two faces: one looking forward and one looking back (Ibid). Social survival and belonging dictate that while tradition is honoured and maintained, migrants must acquire new social skills including new languages and behaviours. This was especially true for the 7 Malaysian nationals, who all felt that an understanding of Malay was important for cultural and political reasons.

\section{Unifying Features of East and South East Asian Students}

On the whole however, the occasions where the respondents felt a greater sense of friendship and identification with East and South East Asian international students were more prominent. Overall, the East and South East Asian heritage becomes a point of entry or contact and enables a solidifying of regional identity. According to Hollinshead (2004), ethnicity in third space populations exists quite independently of their countries of origin and can also be based on shared experiences such as that which is typical of studying in a foreign country. Furthermore as all of them attend university, this means that the experiences they gain will be very specific in regards to the constraints set by the regulated semesters and the requirements of study to negotiate a limited geographical space set within Auckland city.

Beyond their familiar circle of friends and family, many of the respondents talked enthusiastically of the opportunity to meet "Asian friends" as several called it. For one Malaysian brother and sister group, they were able to make more Japanese friends which was of particular interest as their father was Japanese. In addition, the sister has now changed her goals to live and work in Japan upon completion of her doctorate in New Zealand.

Several others had formed some distinct multinational cliques of friends that included a wide variety of East and South East Asian friends. One group in particular consisted of a Korean male, a Japanese male, a Chinese male and two Malaysian females. This group went "everywhere all together" and had even come to the focus group interview in a single group. Although they did not feel these friendships were intimate, they felt they were important as a tool to negotiate their classes and daily life in the hall of residence at university in New Zealand.

Shared values are an important binding feature for these students and the predominance of Confucian values were clearly visible. Cheung (2004), describes key Confucian heritage values among the Chinese diaspora "Those values such as working hard, respect for learning, harmony and family are some of the core values embedded in Confucianism" (p 678). Furthermore these same values are also primary to other East and South East Asian nations such as Japan, South Korea and Vietnam (De Bary, 2000). For the students, these values tend to manifest in their loyalty to their family, their dedication to studies and to maintaining a harmonious attitude in public. These were common themes or values that were clearly evident in the focus groups. In particular, the attention to manners was strictly maintained through the interviews and there were no incidences of interruptions. Most appeared to agree politely, even when their own input several minutes later, was contradictory. For example, while the previously mentioned Chinese respondent declared that diasporic students needed to maintain stronger links with China, there was no obvious disagreement or outrage at that potentially challenging view. While the East and South East Asian respondents did not directly agree, they all acknowledged that it had some value, but was not their own specific view.

Although values were important, traditional religion such as Buddhism held less value for the respondents. The vast majority of the respondents had left their "Buddhist" home country or had no real religious affiliation. One South Korean student declared "Buddhism is for old people like my grandparents". In contrast, Christianity was more actively pursued and one Thai student had "accepted God into his life with New Zealand". Several others had participated in Auckland churches because they felt that Christian New Zealanders were more "friendly". International students are often drawn into churches and the open and caring manner of churches can become significant havens for students living away from their parents for the first time (Myburgh, Neihaus, \& Poggenpoel, 2002). Despite this however, there is some contention as to whether this is funda- 
mental to building a Pan-Asian ethnic identity as churches are already multi-ethnic which is a fundamental feature that makes them welcoming for the students (Henders, 2004).

Ethnic identity is not always chosen positively, but is sometimes selected due to discrimination and racism from other ethnic groups. In the United States, East and South East Asian youth gradually began to choose a Pan-Asian identity partially in reaction to hostility from other, [usually White] youth groups (Zhou \& Lee, 2004). The surrendering of individual national identity for a regional one, in this case was an attractive option for the original ethnic minority groups of Chinese, Koreans, Vietnamese and other groups. But by adopting a Pan-Asian identity the ethnically diverse Asian groups were able to join forces and create social and institutional changes. For the East and South East Asian international students, ethnic separatism in the class room and open racial hostility on the streets can sometimes be an almost daily occurrence. A recurring theme for the sample, particularly the women, reported key instances of men in cars verbally abusing them as they walked down the city streets. As one respondent said "It's OK when they shout, but one time some men threw something wet and sticky at us. I think it was ice-cream". Clearly the respondents are aware of hostility and racism directed at "Asians". Several of the respondents reported that they now described themselves as "Asian" as it is easier in classroom situations to be more general with New Zealanders.

Finally and perhaps most importantly, common aims and participation in the mobilising global knowledge economy plays a primary role in establishing a shared Pan-Asian identity (Huang, 2003; Mok \& Welch, 2002). Although from diverse backgrounds, the respondents were acutely aware that they were all in New Zealand to gain skills that they were unable to access easily from their home-countries and where possible, work experience. Most of the students had applied elsewhere and in particular North America and the United Kingdom, but New Zealand had been the option within their price-range. The cross-section of East and South East Asian international students in this sample found New Zealand a "quiet place" which they found clean and peaceful, but not a place in which they wished to live permanently. New Zealand was considered to be too small and insular although they were enjoying the "clean pure air" as the Taiwanese student described it. Their primary goal is to gain an education in New Zealand, but 8 were expecting to take these qualifications away with them to other western countries where they feel that employment opportunities are more plentiful. Of the 6 students that expected to stay in New Zealand, this was seen as a temporary measure in order to gain work-experience before returning to their country of origin.

\section{A Case for Pan-Asian Identity}

Having established a case for East and South East Asian international Pan-Asian regional identity, it is now important to describe some features of this identity in more detail. As the respondents in this study have been here for varying periods of time, some for several years of secondary school as well as university, it is critical that a fluid element be emphasised. To understand this, it is useful to return to the image of the shopping cart in which we place our cultural values, beliefs, expectations and character (Nagel, 1994). The students rapidly acculturate to the new environment and social allegiances based on a common regional ethnic identity are quickly formed or chosen.

For accuracy however, one must be aware of the forces that drive some of those 'choices' that the students make. Without the framework of common values that is inherent in many East and South East Asian nations, a Pan-Asian ethnic identity formation would be unlikely without these compatible values. Within the family unit, Confucian values are observed and it seems likely that this also compels the students to re-create new family units during their sojourn in New Zealand. At a regional level, there are critical factors at work which present students with a powerful way to consider their differences and their place in the global cultural economy (Appadurai, 2003). These features include developments in technology, economy, media and ideology. In all these areas, the Association of South East Asian Nations (ASEAN) has played a considerable role in developing the ASEAN identity. In addition, strong ties have been forged with East and South East Asian countries in the last 8 years suggesting an extension of cultural inclusion.

"ASEAN is not only a well-functioning, indispensable reality in the region. It is a real force to be reckoned with far beyond the region. It is also a trusted partner of the United Nations in the field of development."

\section{Kofi Annan}

Secretary-General of the United Nations 16 February 2000 (ASEAN Official Website, n.d).

To better understand the influence of ASEAN, a brief history outlining its origin, objectives, collective worth and development is essential. The Association of Southeast and South East Asian Nations or ASEAN was established on August 8, 1967 in Bangkok by five original member countries, namely, Indonesia, Malaysia, Philippines, Singapore, and 
Thailand. Subsequently between 1984 and 1999, it was joined by Brunei Darussalam, Vietnam, Lao PDR, Myanmar and Cambodia. In terms of population, land mass and financial worth and growth, “ the ASEAN region has a population of about 500 million, a total area of 4.5 million square kilometres, a combined gross domestic product of almost US\$ 700 billion, and a total trade of about US\$ 850 billion" (ASEAN website, n.d.).

In its 40 years of existence, ASEAN has achieved its financial, social and cultural objectives. So significant was its political recognition and economic contribution to the region that East and South East Asian countries (China, Japan and the Republic of Korea) sought joint cooperation in December 1997. The ASEAN Plus Three process was officially recognised in 1999. Representatives from attending countries "expressed greater resolve and confidence in further strengthening and deepening East Asia cooperation at various levels and in various areas, particularly in economic and social, political, and other fields" (ASEAN website, 2007).

East and South East Asian students who are aware of the benefits of the greater political, economic and social agendas of their respective countries will naturally relate to the idea of being Asian. Appadurai's (2003) shared "scapes" support this notion of the essential and common values, concerns and interests which bind people of a region. The sense of pride and belonging to a successful group may well define the perception of East and South East Asians who answer to an Asian identity. This coupled with a strong sense of traditions may explain the rationale for students' acceptance of the Asian identity. With acculturation though, there is still the question of negotiating social behaviour and cultural practices.

In their social development in New Zealand, students are exposed to a variety of local and foreign accents as well as behaviours. They need to adapt, appreciate and adopt some of the influences in order to gain recognition and be understood.

\section{Conclusion}

There is clear evidence of a Pan-Asian identity emerging among the East and South East Asian international students in this study. Although heavily influenced by the East and South East Asian regional identity ideology, it is also created from the experiences that the students undergo in New Zealand. While students are notably aware of the cultural differences in the East and South East Asian communities, it does not appear to be a fractious element. If anything this sample suggests that there is a genuine appreciation of cultural diversity as a norm. This may be attributed to the harmonious existence of multi-racial and multi-religious groups in South East Asia. Furthermore, the presence and huge success of ASEAN over the last 40 years may have served as a dormant link which unites citizens of member countries in their shared valuable goals.

In terms of specific shared cultural features, students observe individual traditions and adopt local influences that support rather than contradict their cultural development. The acculturation process shows a desire and respect for the accepted local influences.

Globalization has indeed resulted in the emergence of a Pan-Asian identity based on the notion of a regional 'community'. With its changing nature, feasibility of travel and population shifts, new emerging identities will become a norm. As this study has sought to isolate a Pan-Asian identity, it is important to observe that this necessarily places the students in a context as 'other' to the mainstream population in New Zealand. While all the students in this study have indicated no desire to stay on permanently in New Zealand, it will be useful for future study to examine if, and to what extent these students would consider themselves "Kiwi" at this stage of their study; and to measure further developmental identity changes during the course of their study.

\section{References}

Appadurai, A. (2003). Disjuncture and difference in the global cultural economy. In J. Evans Braziel \& A. Mannur (Eds.), Theorizing diaspora (pp. 25-48). Malden, MO: Blackwell Publishing Ltd.

Association of South East Asian Nations. (n.d.). The official web site of the Association of South East Asian nations (ASEAN). Retrieved July 10, 2007, fromhttp://www.aseansec.org/

Cheung, G. C. K. (2004). Chinese diaspora as a virtual nation: Interactive roles between economic and social capital. Political Studies, 52, 664-684.

Cochrane, A., \& Pain, K. (2004). A globalizing society? In D. Held (Ed.), A globalizing world? Culture economics, politics (2nd ed., pp. 5-47). London: Routledge.

De Bary, W. M. T. (2000). Asian values and human rights: A Confucian communitarian perspective. Cambridge, MA: Harvard University Press.

Henders, S. J. (2004). Political regimes and ethnic identity in East and Southeast Asia: Beyond the "Asian Values" debate. In S. J. Henders (Ed.), Democratization and identity. Regimes and ethnicity in East and Southeast Asia (pp. 124). Lanham, MD: Lexington Books.

Hollinshead, K. (2004). Tourism and third space populations. In T. Coles \& D. J. Timothy (Eds.), Tourism, diaspora and space (pp. 33-49). London: Routledge Taylor and Francis Group. 
Huang, F. (2003). Policy and practice of internationalization of higher education in China. Journal of Studies in International Education, 7(3), 225-240.

McKay, H. (2004). The globalization of culture? In D. Held (Ed.), A globalizing world? Culture, economics and politics (2nd ed., pp. 47-84). London: Routledge.

Mok, K. H., \& Welch, A. R. (2002). Economic rationalism, managerialism and structural reform in education. In K. H. Mok \& D. K. Chan (Eds.), Globalization and education. The quest for quality education in Hong Kong (pp. 23-40). Hong Kong, China: Hong Kong University Press.

Myburgh, C. P. H., Neihaus, L., \& Poggenpoel, M. (2002). International learners' experiences and coping mechanisms within a culturally diverse context. Education ChulaVista, 123(1), 107-129.

Nagel, J. (1994). Constructing ethnicity: Creating and recreating ethnic identity and culture. Social Problems, 41(1), 152176.

Nguyen, T.-H., \& King, B. (2004). The culture of tourism in the diaspora. The case of Vietnamese community in Australia. In T. Coles \& D. J. Timothy (Eds.), Tourism, diasporas and space (pp. 172-187). London: Routledge Taylor and Francis Group.

Tu, W.-m. (1994). Cultural China: The periphery as the center. In W.-m. Tu (Ed.), The living tree. The changing meaning of being Chinese today (pp. 1-34). Stanford, California: Stanford University Press.

Ward, C. (2005). The impact of international students on domestic students and host institutions [Electronic Version]. Research Report 2005. Retrieved October 19, 2005, from http://www.minedu.govt.nz/index.cfm?layout=document\&documentid=5643\&data=1\#P718_115724: Ministry of Education.

Weiwen, Z., \& Qingnan, Z. (1993). In search of China's minorities. Beijing, China: New World Press.

Zhou, M., \& Lee, J. (2004). The making of culture, identity and ethnicity among Asian American youth. In J. Lee \& M. Zhou (Eds.), Asian American youth: Culture identity and ethnicity (pp. 1-32). New York: Routledge.

\section{About the Authors}

S. Jeanie Benson

My research interest has built from my interactions with East Asian youth particularly in the area of international education and martial arts. My current research interests are in East Asian international student experience in New Zealand, Asianisation, sociology of the media and intercultural adaptation.

\section{Khairiah A Rahman}

I am interested in investigating the New Zealand social experiences and cultural adaptation of students from Asia. I am also looking into the teaching and learning considerations affecting communication students from Asia. My research interests stem from my cosmopolitan ancestry as well as my own teaching and working background, having lived in Europe, Asia and New Zealand. 



\section{THE INTERNATIONAL JOURNAL OF DIVERSITY IN ORGANISATIONS, COMMUNITIES AND NATIONS}

\section{EDITORS}

Mary Kalantzis, University of Illinois, Urbana-Champaign, USA.

Paul James, RMIT University, Australia

\section{EDITORIAL ADVISORY BOARD}

Ien Ang, University of Western Sydney, Australia.

Samuel Aroni, University of California, Los Angeles, USA.

Duane Champagne, University of California, Los Angeles, USA.

Guosheng Y. Chen, RMIT University, Melbourne, Australia.

Jock Collins, University of Technology, Sydney, Australia.

Bill Cope, University of Illinois, Urbana-Champaign, USA.

Heather Marion D'Cruz, Deakin University, Geelong, Australia.

James Early, Smithsonian Institution, Washington, DC, USA.

Denise Egéa-Kuehne, Louisiana State University, Baton Rouge, USA.

Amareswar Galla, Australian National University, Canberra, Australia.

Barry Gills, University of Newcastle, UK.

Jackie Huggins, University of Queensland, Australia.

Andrew Jakubowicz, University of Technology, Sydney, Australia.

Ha Jingxiong, Central University of Nationalities, Beijing, China.

Peter McLaren, University of California, Los Angeles, USA.

Joe Melcher, Xavier University of Louisiana, New Orleans, USA.

Greg Meyjes, Solidaris Intercultural Services L.L.C, Falls Church, VA, USA.

Walter Mignolo, Duke University, USA.

Brendan O'Leary, University of Pennsylvania, USA.

Aihwa Ong, University of California, Berkeley, USA.

Peter Phipps, RMIT University, Melbourne, Australia.

Ronald Prins, Managing Director, Bos en Lommer Neighbourhood Council, The Netherlands.

Peter Sellars, Theatre, Opera and Film Director.

Michael Shapiro, University of Hawai'i, USA.

David S. Silverman, Valley City State University, North Dakota, USA.

Martijn F.E. Stegge, Diversity Platform, City of Amsterdam, The Netherlands.

Geoff Stokes, Institute for Citizenship and Globalisation, Deakin University, Melbourne, Australia.

Terry Threadgold, Cardiff University, Wales, UK.

Mililani Trask, Indigenous Expert to the Permanent Forum on Indigenous Issues for the Economic Council of the UN Assembly, Hawai'i, USA.

Marij Urlings, Dean, School of Health Inholland University, Amsterdam-Diemen, The Netherlands.

Joanna van Antwerpen, Director, Research and Statistics, City of Amsterdam, The Netherlands.

Grethe van Geffen, Seba Cultuurmanagement, Amsterdam, The Netherlands.

Rob Walker, Keele University, UK.

Ning Wang, Tsinghua University, Beijing, China.

Owens Wiwa, African Environmental and Human Development Agency, Toronto, Canada.

Please visit the Journal website at http://www.Diversity-Journal.com for further information:

- $\quad$ ABOUT the Journal including Scope and Concerns, Editors, Advisory Board, Associate Editors and Journal Profile

- $\quad$ FOR AUthORs including Publishing Policy, Submission Guidelines, Peer Review Process and Publishing Agreement

SUBSCRIPTIONS

The Journal offers individual and institutional subscriptions. For further information please visit http://ijd.cgpublisher.com/subscriptions.html. Inquiries can be directed to subscriptions@commongroundpublishing.com

INQUIRIES

Email: cg-support@commongroundpublishing.com 